\title{
Access and Uses of Free Maternal Health Care Services Among Women in Urban West Zanzibar
}

\author{
Hannat Said Abdul-Rahman ${ }^{1} \quad$ Mamudu Dafay $^{2} \quad$ Abdalla Ussi Hamad ${ }^{3}$ \\ 1.MSc in Economic and Finance Student \\ 2.Lecturer, Department of Economics, Zanzibar University \\ 3.Head and Lecture, Department of Economics, Zanzibar University
}

\begin{abstract}
The main objective of this study was to examine the access ad uses of free maternal health care services among women in Zanzibar Urban West Region. A quantitative approach adopted in this study and data was analyzed through descriptive statistical analysis. Simple Random and purposive sampling were used to select 262 Respondents. The data were collected through closed ended questionnaires. The findings of the study revealed that, Most of hospitals and clinics visited by maternal mothers were government clinics since 196 respondents which is equal to $(74.8 \%)$ visited Government clinic, 66 respondents equal to $(25.1 \%)$ visited private clinics and. In addition the study found that more than $80 \%$ of the total respondents were having access and uses of the service provided by the health centers during their pregnancy period. The government of Zanzibar through Ministry of Health should take the special measure to emphasis on the improvement of free maternal health care services in health centres. This may help maternal mother and infants' to get good treatment.
\end{abstract}

Keywords: Access and Uses, Free Maternal Health Care Services, Descriptive Statistics, Urban west Zanzibar DOI: $10.7176 / \mathrm{JHMN} / 85-07$

Publication date: January $31^{\text {st }} 2021$

\section{Introduction}

Maternal health care service has been among the most important interventions to decrease maternal morbidity and mortality. According to the World Health Organization (WHO) clarified that maternal health refers to the health of women during pregnancy, childbirth and the postnatal period, where by each stage should be a positive experience, ensuring women and their babies reach their full potential for health and well-being. The Maternal Health Task Force (2015) shows that, The United States (U.S.) fares worse in preventing pregnancy-related deaths than most other developed nations. Despite of participating in the Millennium Development Goals (MDGs) and spending more than any other country on hospital-based maternity care, the maternal mortality ratio (MMR) in the U.S. remains at about 17 deaths per 100,000 live births. Between 2000 and 2017, the global MMR decreased by $38 \%$. The U.S. has also failed to meet prior national goals for maternal mortality reduction and did not meet the modest Healthy People 2020 goal of reducing maternal mortality by $10 \%$ between 2007 and 2020 .

In Zanzibar, as a case study, health sector includes three levels of care and corresponding facilities as follows: a) Primary level: Health Care Units and Centre (PHCUs, PHCU+ and Primary Health Care Centre-PHCCs) b) Secondary level: District Hospitals c) Tertiary level: Mnazi Mmoja National Hospital. PHCUs provide Primary health care services, PHCU+ are selected to provide additional services such as delivery, dental, laboratory and pharmacy services. PHCCs provide the same services as PHCU+ with the addition of inpatient and X-ray services. District hospitals provide second line referral services, including basic surgery and the tertiary hospital (MnaziMmoja Hospital) provides referral services.

In addition, the issue of maternal in Zanzibar has markedly been contributed by limited access to quality health services, poor referral system, inadequate availability of commodities, equipment and supplies, and inadequate funding envelope for $\mathrm{MNCH}$ services. Other factors include: inadequate involvement and participation of community in planning, some negative socio-cultural beliefs and practices [myths and misconceptions], gender inequalities, poor health care seeking behaviors, inadequate meaningful involvement of males in planning and offering of $\mathrm{MNCH}$ services and low household education and income. The national response to reducing maternal is articulated in the MKUZA and operationalized through the National Road Map Strategic Plan (2008 - 2015) whose primary objective is to accelerate the free maternal health care service in Zanzibar. Accordingly, the Revolutionary Government of Zanzibar has identified Maternal, Newborn and Child Mortality Reduction (MNMR) as one of its priorities and it is featuring in the Zanzibar Strategy for Growth and Reduction of Poverty (ZSGRP). 
Table 1. Number of mothers delivered at facilities and number of maternal death occurred

\begin{tabular}{|l|r|r|r|r|r|r|r|r|}
\hline \multirow{2}{*}{ Health facilities } & \multicolumn{4}{|l|}{ Number of mothers delivered at facilities } & \multicolumn{4}{l}{$\begin{array}{l}\text { Number } \\
\text { occurred at facilities }\end{array}$} \\
\cline { 2 - 11 } & \multicolumn{1}{|c|}{$\mathbf{2 0 1 5}$} & $\mathbf{2 0 1 6}$ & $\mathbf{2 0 1 7}$ & $\mathbf{2 0 1 8}$ & $\mathbf{2 0 1 5}$ & $\mathbf{2 0 1 6}$ & $\mathbf{2 0 1 7}$ & $\mathbf{2 0 1 8}$ \\
\hline MnaziMmoja & 10,983 & 11,235 & 13,383 & 15,733 & 72 & 252 & 94 & 86 \\
\hline Muembeladu & 5,866 & 5,816 & 6,867 & 5,475 & 24 & 107 & 24 & 57 \\
\hline Chukwani & 257 & 365 & 198 & 208 & - & 2 & 11 & 3 \\
\hline Fuoni & 725 & 868 & 1,211 & 687 & 3 & 7 & 11 & 6 \\
\hline Total & $\mathbf{1 7 , 8 3 1}$ & $\mathbf{1 8 , 2 8 4}$ & $\mathbf{2 1 , 6 5 9}$ & $\mathbf{2 2 , 1 0 3}$ & $\mathbf{9 9}$ & $\mathbf{3 6 8}$ & $\mathbf{1 4 0}$ & $\mathbf{1 5 2}$ \\
\hline
\end{tabular}

\section{Problem of the paper}

Access and uses of free maternal health care service varies across countries, communities, and individuals, largely influenced by social and economic conditions as well as health policies (Porter, Eduardo 2017). According to the World Health Organization (WHO), a well-functioning health care system requires a financing mechanism, a well-trained and adequately paid workforce, reliable information on which to base decisions and policies, and well maintained health facilities to deliver quality medicines and technologies.

In order to improve the health of mother and children, the Zanzibar government establishes several strategies such as free maternal health care system. Since 1964, the Revolutionary Government of Zanzibar declared free maternal health care service so as to make mothers and infants survive during child birth. Also, the Zanzibar health policy of 2011 was introduced to enhance free maternal health care service so as to increase effectiveness to the women during their delivery.

During the implementation of these strategies and policy, there still some challenges which government faced. There has been continuous problem of maternity health mortality rate in Zanzibar whereby a number of mothers and their infants dying during their delivery. Health Bulletin of Ministry of health of Zanzibar demonstrate that in 2015 number of mother delivered at four selected Government facilities were 17,831 where by 99 dead. In 2016 18,284 was the number of mother delivered at facilities where by 368 were dead. In 2017 number of mother delivered at facilities were 21,659 where by 140 dead. Also, in 2018 number of mother delivered at facilities were 22,103 where by 152 were dead.

The existence of high rate of maternal mortality in 2015, 2016, 2017 and 2018 is what lead the researcher to undertake the study which assesses the access and uses of free maternal health care services among women in urban west Zanzibar.

\section{Theoretical literature review}

\subsection{Attribution theory}

Attribution theory, as applied to health care management, is a way of assessing the successes and failures of a health care system or program. In Patrick Palmieri and Lori Peterson's "To Err is Human: Building a Safer Health Care System" (2009), attribution theory is described as one possible health care management theory that can be used to create a safer environment for patients. Although not fully developed as a health care management theory, the authors suggest that attribution theory can be used as a conceptual framework to foster a positive and safe work environment for both health care workers and patients.

\subsection{Evidence-Based Theory}

A second health care management theory is the evidence-based management theory. A 2001 report by K. Walshe and T.G. Rundall at the University of Birmingham suggests that health care managers have been slow to accept and apply the same theories to which they often hold health care workers, an evidence-based approach that requires doctors, nurses and other health care professionals to make decisions based on the best available evidence.

\subsection{Utilization Theory}

Utilization theory is a third health care management theory, one that has received wider application in the health care industry than the more theoretical attribution and evidence-based theories. Utilization management is a proactive approach to managing health care through preset guidelines. The American College of Medical Quality identifies several tasks in utilization management that are essential to effective management of a health care organization.

\section{Empirical literature review}

Ranjan Kumar Prusty (2014) conducted a study on Utilization of maternal health care services and reproductive health complications in Assam, India. Maternal health services potentially play a significant role in improving reproductive health. Access to skilled assistance and well-equipped health institutions during delivery can reduce maternal mortality and morbidity and improve pregnancy outcomes. In this study, the researcher examined the 
relationship between the use of maternal health care services and the frequency of reproductive health complications (during pregnancy, delivery and after delivery) in Assam. Subject and methods: they used data from the third round of the District Level Household and Facility Survey (DLHS, 2007-2008) which collects information about reproductive and child health services. Descriptive and multivariate analyses were used to understand the relationship between the use of health care services and the frequency of complications in pregnancy. Results: Findings show that more than half of women reported having any complication during pregnancy and delivery.

Babker El Shiekh1(2015) conducted a study on the factors influencing the utilization of maternal health care services by nomads in Sudan. Sudan has high maternal mortality. The rate among nomads - groups of people who move from place to place as a way of obtaining food, finding pasture or make a living - is very high and varies between different regions of the country. The objective of the study is to identify the factors affecting the utilization of maternal health care services by nomadic communities in Sudan, to make recommendations to improve their health. Nomadic health practices and health care services are the main influencing factors affecting the utilization of maternal health care services. Nomadic health practices are influenced by the mobile lifestyle of nomads, their low level of education and knowledge, gender norms, beliefs, values and attitudes, and their geographical locations. Existing health care services are ill-adapted to the nomadic lifestyle.

Krishna Kumar Aryal (2018) conducted a study on Quality of Care and Client Satisfaction with Maternal Health Services in Nepal. This report presents further analysis of the 2015 Nepal Health Facility Survey. Data analysis is based on the Donabedian framework for assessing quality of care in health services, which divides the indicators into three groups: structure, process, and outcome. The World Health Organization Service Availability and Readiness Assessment (SARA) indicator guideline was used to assess facility service readiness, service quality and client satisfaction with maternal health services. The study performed both bivariate and multivariate regression analysis to examine the association of maternal health service readiness and quality indicators with client satisfaction. The analysis revealed that $38 \%$ of antenatal care clients were very satisfied with the services provided at the health facility. Aspects such as nonpayment of service fees, sex of service provider, and regularity of conducting facility management committee meetings were significant predictors for client satisfaction with antenatal care services.

\section{Conceptual framework}

Conceptual frame work refers to the administration of materials or concepts obtained from revised theories. According to Jabareen (2009) indicate that "conceptual framework as a network, or "a plane" of interconnected ideas that organize to deliver a complete understanding of a phenomenon. Due to this research, the researcher tries to indicate the interlinked between concepts of access and uses and free maternal health care services

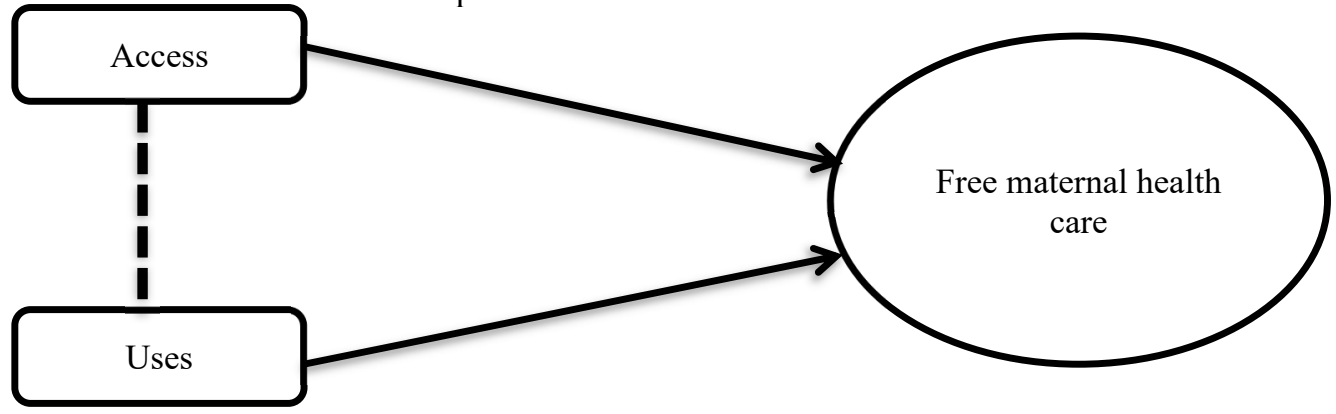

Figure 1. Conceptual Framework

\section{Methodology}

This part discusses research methodology which was employed in this study.

Research design: The study employs a quantitative research design. In this design, it allows the researchers to explore, explain a phenomenon, and interpret data statistically in a wider and easy ways. Employing this research design has enabled the researcher to solve the issue at hand.

Study area: This study conducted in Urban West Region Unguja. The selected centres which involved in this study are "MnaziMmoja"Hospital, "Muembeladu" hospital, "Chukwani" Cottage and "Fuoni" Cottage. The main reasons leading to the selection of Urban West Region was that the area has largest number of women who have been attended in these hospitals for a very longtime.

Study population, sampling techniques and sample size: The target population of this study were women who get free maternal health service which provided by Government runs Hospital ("MnaziMmoja" Hospital, "Muembeladu" hospital, "Chukwani" Cottage and "Fuoni" Cottage). Simple random and purposive were used to select 262 sample size of this study.

Data collection tools: Questionnaire was distributed to 262 respondents as sample size of this study. This tool was 
used because the researchers were able to manage the collection of information from a large number of people in a short period of time and in a relatively cost effective way.

Tools of analysis: Since the study qualitative in nature, therefore, the information gathered was analyzed quantitatively and qualitatively. The data collected were imputed using SPSS$_{23}$ and descriptive statistical analysis was employed to determine the access and uses of free maternal health care service in Urban West Region, Unguja.

\section{Findings and discussion}

\subsection{Demographic of the respondents}

The respondents were identified by only demographic factors, these are; age and education level.

By age, the researcher divided the age group into four groups and most of the respondents fall under age group of 26 to 30 years which represents 45 percent. This is because this age group is the most reproductive ages in any country. It is followed by 31 to 25 and 18 to 25 which is almost the same 25.2 and 24.8 percent respectively.

Through education, the respondents were evenly distributed on the level of education. Primary level was 81 respondents which is equal to $(30.9 \%)$ while in secondary level were 76 equal to $(29 \%)$. The data also revealed that most of the respondents were in University level about 92 constitute $(35.1 \%)$ of the total respondents. While only 13 constitutes $(5 \%)$ were not educated.

Table 2 Demographic of the respondents

\begin{tabular}{|l|l|l|l|}
\hline Variable & Category & Frequency & Percentage (\%) \\
\hline \multirow{5}{*}{ Age } & $18-25$ & 65 & 24.8 \\
& $26-30$ & 118 & 45 \\
& $31-35$ & 66 & 25.2 \\
& 36 and above & 13 & 5 \\
\hline \multirow{5}{*}{ Education } & Primary & 81 & 30.9 \\
& Secondary & 76 & 29.0 \\
& University & 92 & 35.1 \\
& None of the above & 13 & 5 \\
\hline
\end{tabular}

\subsection{Access and uses of free maternal health care services}

The access and utilization of various free maternal health care services among women in urban west Zanzibar was described. The respondents were supposed to describe if they have accessed and utilize any of free maternal health care services through various questions as followed.

\section{a) Health Care Centers Visited by Maternal Mother}

The researchers were interested to know the numbers which visited health Care Centers by Maternal Mother and the following result were obtained and shown in table 3.

Table 3: Health care centers visited by Maternal Mother

\begin{tabular}{|l|c|c|}
\hline \multicolumn{1}{|c|}{ Health Care Centers } & Frequency & Percent \\
\hline Mnazi mmoja Hospital & 100 & 38 \\
\hline Mwembeladu Hospital & 87 & 33 \\
\hline Fuoni Hospital & 50 & 19 \\
\hline Chukwani Hospital & 25 & 10 \\
\hline Total & $\mathbf{2 6 2}$ & $\mathbf{1 0 0 . 0}$ \\
\hline
\end{tabular}

Source: Field Data, 2020

Table 3 summarized the results concerning the health care centers visited by maternal mother. The results of the study showed that, 100 respondents which is equal to (38.1\%) visited Mnazi Mmoja Hospital, 87 respondents equal to (33.2\%) visited Mwembeladu Hospital, 50 respondents equal to (19.0\%) visited and $25(9.5 \%)$ visited in Chukwani. Due the study results it is vividly indicated that, most of the maternal mother visited Health care centers during maternity period.

b) Duration Visiting Clinic during Pregnancy

In this part, respondents were asked by the researcher to mention the time that was most visited he clinics during their pregnancy. The results obtained from this question described clearly in Table 4

Table 4: Times did the pregnancy mother visited the clinics

\begin{tabular}{|l|c|c|}
\hline \multicolumn{1}{|c|}{ Duration } & Frequency & Percent \\
\hline 1 to 3 times & 91 & 34.7 \\
\hline More than 3 times & 171 & 65.3 \\
\hline Total & $\mathbf{2 6 2}$ & $\mathbf{1 0 0 . 0}$ \\
\hline
\end{tabular}

Source: Field Data, 2020

The results obtained from Table 4 shows that, 91 respondents which is equal to $(34.7 \%)$ visited 1 to 3 times, but 171 respondents which is equal to $(65.3 \%)$ visited more than 3 times. Therefore, the study vividly indicated 
that, most of the pregnancy mothers were visited at clinics more than 3 times up to their delivery, since more than $(60 \%)$ of the total respondents replied.

\section{c) Health Services Received During Pregnancy}

In this part of the study, respondents were asked to mention the types of health services they received during pregnancy period. The results are shown clearly in Table 5.

Table 5: Health Services Received During Pregnancy

\begin{tabular}{|l|c|c|}
\hline \multicolumn{1}{|c|}{ Types of Health Services } & Frequency & Percent \\
\hline Physical examination & 190 & 72.5 \\
\hline Gynecological examination & 52 & 19.8 \\
\hline Ultrasound & 20 & 7.6 \\
\hline Total & $\mathbf{2 6 2}$ & $\mathbf{1 0 0 . 0}$ \\
\hline
\end{tabular}

Source: Field Data, 2020

The summarized results from Table 4.5 shows that, out of 262 respondents, 190 which is equal to (72.5\%) received physical examination, while 52 respondents equal to $(19.8 \%)$ received gynecological examination, but $20(7.6 \%)$ received ultrasound. Therefore, due to these results, it is clearly shown that, majority of pregnant mother almost $(72,5 \%)$ of the total respondents received physical examination.

\section{d) Satisfaction of the Services Received}

In this part of the objective, respondents were asked to identify whether completely satisfied, partially satisfied or dissatisfied on the services received during pregnancy period. The results are summarized in Table 6 .

Table 6: Rate of satisfaction on the Services Received

\begin{tabular}{|l|c|c|}
\hline \multicolumn{1}{|c|}{ Rate of Satisfaction } & Frequency & Percent \\
\hline Completely satisfied & 27 & 10.3 \\
\hline Partially satisfied & 222 & 84.7 \\
\hline Dissatisfied & 13 & 5.0 \\
\hline Total & $\mathbf{2 6 2}$ & $\mathbf{1 0 0 . 0}$ \\
\hline
\end{tabular}

Source: Field Data, 2020

The summarized results from Table 6 revealed that, 27 respondents which is equal to $(10.3 \%)$ were completely satisfied, while, 222 respondents equal to $(84.7 \%)$ were partially satisfied, and those who were dissatisfied were 13 equal to (5\%). Therefore, due to study results, it is vividly indicated that, more than $80 \%$ of the total respondents were partially satisfied of the service provided by the health centers during their pregnancy period.

e) Types of Health Services Received after Delivery

In this part of the research, respondents were required to identify types of health services that they received after having delivery. The results are summarized in Table 7

Table 7: Types of health services received after delivery

\begin{tabular}{|l|c|c|}
\hline \multicolumn{1}{|c|}{ Types of Health services } & Frequency & Percent \\
\hline Physical examination & 157 & 59.9 \\
\hline Counseling on breastfeeding & 79 & 30.2 \\
\hline Nutritional supplements & 13 & 5.0 \\
\hline Information on warnings signs of problems & 13 & 5.0 \\
\hline Total & $\mathbf{2 6 2}$ & $\mathbf{1 0 0 . 0}$ \\
\hline
\end{tabular}

Source: Field Data, 2020

Table 7 summarized the results obtained in the field about types of health services received after women got delivery. The results of the study showed that, 157 respondents which is equal to $(59.9 \%)$ received physical examination, while 79 respondents equal to $(30.2 \%)$ received counseling on breast feeding, but $13(5 \%)$ received nutritional supplements and those who received information on warning signs of problems were 13 equal to (5\%). Therefore, it is vividly indicated that, most of the respondents received physical examination services since it made more than $(50 \%)$ of the total respondents.

\section{f) Satisfaction on Physical Examination service}

In this part of specific objective, respondents were asked to rate on the level of satisfaction about the physical examination they received, whether completely satisfied, partially satisfied or dissatisfied. The results are summarized in Table 8. 
Table 8: Physical Examination Services

\begin{tabular}{|l|c|c|}
\hline \multicolumn{1}{|c|}{ Level of Satisfaction } & Frequency & Percent \\
\hline Completely Satisfied & 209 & 79.8 \\
\hline Partially satisfied & 40 & 15.3 \\
\hline Dissatisfied & 13 & 5.0 \\
\hline Total & $\mathbf{2 6 2}$ & $\mathbf{1 0 0 . 0}$ \\
\hline
\end{tabular}

Source: Field Data, 2020

Table 8 summarized the findings concerning physical examination services provided in health centers. The findings revealed that, out of 262 respondents, 209 equal to $(79.8 \%)$ were completely satisfied, whereby, $40(15.3 \%)$ were partially satisfied and those respondents who were dissatisfied with physical examination provided were 13 $(5 \%)$. Therefore, this is to say that, physical examination was almost good since most of respondents in the field were satisfied, which made almost $(79.8 \%)$ of the total respondents.

\section{g) Gynecological examination}

In this part of the study objective, respondents were asked to rate on the level of satisfaction about the Gynecological examination they received, whether completely satisfied, partially satisfied or dissatisfied. The results are summarized in Table 9

Table 9 Gynecological examination

\begin{tabular}{|l|c|c|}
\hline \multicolumn{1}{|c|}{ Level of Satisfaction } & Frequency & Percent \\
\hline Completely Satisfied & 13 & 5.0 \\
\hline Partially satisfied & 118 & 45.0 \\
\hline Dissatisfied & 131 & 50.0 \\
\hline Total & 262 & 100.0 \\
\hline
\end{tabular}

Source: field Data, 2020

The summarized results from Table 9 about the Gynecological examination showed that, out of 262 respondents 13 equal to (5\%) were completely satisfied, 118 respondents $(45 \%)$ partially satisfied and those who were dissatisfied were $131(50 \%)$. Therefore, due to the results indicated above, this is to say that, most of the respondents were not satisfied with Gynecological service provided at the health centers.

h) Ultrasound Services

In this part of the study objective, respondents were asked to rate on the level of satisfaction about the Ultrasound services provided, whether completely satisfied, partially satisfied or dissatisfied. The results are summarized in Table 10

Table 10 Ultrasound Services

\begin{tabular}{|l|c|c|}
\hline \multicolumn{1}{|c|}{ Level of Satisfaction } & Frequency & Percent \\
\hline Completely Satisfied & 118 & 45.0 \\
\hline Partially satisfied & 131 & 50.0 \\
\hline Dissatisfied & 13 & 5.0 \\
\hline Total & 262 & 100.0 \\
\hline
\end{tabular}

Source: Field Data, 2020

The summarized results from Table 10 about the Ultrasound services showed that, out of 262 respondents 118 equal to $(45 \%)$ were completely satisfied, 131 respondents $(50 \%)$ partially satisfied and those who were dissatisfied were $13(5 \%)$. Therefore, due to the results indicated from Table 10 mean to say that, most of the respondents were partially satisfied with Ultrasound service provided at the health centers.

\section{i) HIV/AIDS Testing Services}

In this part of the study specific objective, respondents were required to rate on the level of satisfaction about the HIV/AIDS testing services provided, whether completely satisfied, partially satisfied or dissatisfied. The results are clearly described in Table 11

Table 11 HIV/AIDS Testing Services

\begin{tabular}{|l|r|r|}
\hline \multicolumn{1}{|c|}{ Level of Satisfaction } & Frequency & \multicolumn{2}{c|}{ Percent } \\
\hline Completely Satisfied & 144 & 55.0 \\
\hline Partially satisfied & 92 & 35.1 \\
\hline Dissatisfied & 26 & 9.9 \\
\hline Total & $\mathbf{2 6 2}$ & $\mathbf{1 0 0 . 0}$ \\
\hline
\end{tabular}

The summarized results from Table 11 about the HIV/AIDS services showed that, out of 262 respondents 144 equal to $(55 \%)$ were completely satisfied, 92 respondents $(35.1 \%)$ partially satisfied and those who were dissatisfied were 26 (9.9\%). Therefore, due to the results indicated from Table 4.13, mean to say that, most of the respondents were completely satisfied with HIV/AIDS testing service provided at the health centers. 


\section{Conclusion}

The main concern of this study was to examine the access to and utilization of free maternal health care services among women in urban west Zanzibar. The study found that, most of the maternal mother visited Government centers during maternity period rather than private centers, since it made more than $(70 \%)$. Also the stud indicated that, most of the pregnancy mothers were visited at clinics more than 3 times up to their delivery. Then, the study clearly shown the majority of pregnant mother almost $(72,5 \%)$ of the total respondents received physical examination. Apart from that, study results, it is vividly indicated that, more than $80 \%$ of the total respondents were partially satisfied of the service provided by the health centers during their pregnancy period. Also, it is vividly indicated that, most of the respondents received physical examination services since it made more than $(50 \%)$ of the total respondents. In addition, the study found that, physical examination was almost good since most of respondents in the field were satisfied, which made almost (79.8\%) of the total respondents. On breastfeeding, most of the respondents were completely satisfied with counseling on breastfeeding. About contraceptives, the results indicated above, this is to say that, most of the respondents were partially satisfied with contraceptives service provided at the health centers. Also, most of the respondents were not satisfied with Gynecological service provided at the health centers. About ultrasound, the results indicated that, most of the respondents were partially satisfied with Ultrasound service provided at the health centers. On HIV/AIDS services the results indicated that, most of the respondents were completely satisfied with HIV/AIDS testing service provided at the health centers.

\section{Recommendations}

The study recommend that, efforts should be made to strengthen maternal health care's services attendance, with the expectation that this will lead to higher use of health facility delivery services. This will contribute to increase the use of delivery services and increased uptake of post-delivery services.

In remote areas with limited access to health facilities, regional and district health planning and programming should consider alternative and innovative strategies and interventions to ensure remote communities have access to maternal health care services, delivery, and postpartum services.

\section{References}

Abdulraheem, B. I., Olapipo, A. R., \&Amodu, M. O. (2012). Primary health care services in Nigeria: Critical issues and strategies for enhancing the use by the rural communities. Journal ofpublic health and epidemiology, 4(1), 5-13.

Ajayi, A.I., Akpan, W. (2020) Maternal health care services utilisation in the context of 'Abiye' (safe motherhood) programme in Ondo State, Nigeria. BMC Public Health 20, 362 https://doi.org/10.1186/s12889-020-08512$\mathrm{Z}$

Baicker, 2017\&Zaslavsky, A. M. (2017). The economics of public health: Missing pieces to the puzzle of health service reform. Health Services Research, 52, 2275-2284.

Busse, R., Riesberg, A., \& World Health Organization. (2004). Health care systems in transition: Germany (No. EUR/04/5046928). Copenhagen: WHO Regional Office for Europe.

Dolton J. (2016) (2016). Lewis acid-base adduct approach for high efficiency perovskite solar cells. Accounts of chemical research, 49(2), 311-319.

Kolstad, J. R. (2011). How to make rural jobs more attractive to health workers. Findings from a discrete choice experiment in Tanzania. Health economics, 20(2), 196-211.

Lawan (2012) Jun, M. (2012). International profiles of health care systems 2012: Australia, norway, sweden, switzerland, and the united states.

McIntyre, D. (2008). "Beyond fragmentation and towards universal coverage: insights from Ghana, South Africa and the United Republic of Tanzania". Bulletin of the World Health Organization. 86: 871-876

Mian, N.u., Alvi, M.A., Malik, M.Z. et al. (2018) Approaches towards improving the quality of maternal and newborn health services in South Asia: challenges and opportunities for healthcare systems. Global Health 14, 17 https://doi.org/10.1186/s12992-018-0338-9

Olonade, O., Olawande, T. I., Alabi, O. J., \& Imhonopi, D. (2019). Maternal Mortality and Maternal Health Care in Nigeria: Implications for Socio-Economic Development. Open access Macedonian journal of medical sciences, 7(5), 849-855. https://doi.org/10.3889/oamjms.2019.041

Porche, D. J. (2017). Health Policy. Jones \& Bartlett Learning.

Porter, Eduardo (2017-08-29). "Home Health Care: Shouldn't It Be Work Worth Doing?". The New York Times. ISSN 0362-4331. Retrieved 2017-11-29.

Sommers, Benjamin D.; Gawande, Atul A.; Baicker, Katherine (2017). "Health Insurance Coverage and Health — What the Recent Evidence Tells Us". New England Journal of Medicine. 377 (6): 586-593.

WHO, World Health Report: Health Syetem Financing: The Path to Universal Coverage. 2010: Geneva.

William \& Russell, G. M. (2016). Interprofessional teamwork innovations for primary health care practices and practitioners: evidence from a comparison of reform in three countries. Journal of multidisciplinary 
healthcare, 9, 35 .

Winnie Yip, 2015).Ameh, E. A. \&Mérisier, E. D. (2015). Global Surgery 2030: evidence and solutions for achieving health, welfare, and economic development. The Lancet, 386(9993),

Yip, W., Hafez, R., \& World Health Organization. (2015). Improving Health System Efficiency: Reforms for improving the efficiency of health systems: lessons from 10 country cases (No. WHO/HIS/HGF/SR/15.1). World Health Organization. 